\title{
An analysis of corporate board networks in South Africa
}

\author{
I.N. Durbach \\ Department of Statistical Sciences, University of Cape Town, \\ Private Bag, Rondebosch 7701, Republic of South Africa \\ ian.durbach@uct.ac.za \\ H. Parker \\ Graduate School of Business, University of Cape Town, \\ Private Bag, Rondebosch 7701, Republic of South Africa \\ hamiedap@gsb.uct.ac.za
}

Received April 2009

\begin{abstract}
In this paper we analyse the networks created from directors sitting on the boards of companies in South Africa. We consider two projections of this network: a director network, in which only directors are present and two directors are linked if they sit together on one or more common boards; and a firm network, in which only firms are present and an edge indicates that the two firms share one or more directors. We describe these networks in terms of the statistical properties that they possess, and compare them to theoretical values obtained under various random network models. The network analysis is the first to be applied to a relatively small emerging economy like South Africa. We find that many of the features previously found to hold for highly-developed countries also apply here, suggesting that corporate networks may be fairly robust to stages of economic development.
\end{abstract}

*To whom all correspondence should be addressed.

\section{Introduction}

Boards of directors have been the focus of much research in the management sciences. Possible reasons for this interest are not hard to discern. Firstly, the directors sitting on the board of a firm are in a position to exercise at least some control over the strategic direction taken by the firm, so that by studying boards of directors we hope to gain some insight into the reasons for the differences and similarities we observe in corporate strategy, and thus better understand the corporate world as a whole. Secondly, boards of directors often overlap with one another, wherever a board member affiliated with one firm sits on the board of directors of another firm. Firms having one or more directors in common are 'interlocked', and the network created by many such interlocking directorates offers 'a potent medium for the spread of corporate practice and structures' (Davis, Yoo \& Baker, 2003). Moreover, for publicly traded firms at least, information on board membership is abundant, reliable and readily available, so that it is possible to reconstruct the complete network of firms and their inter-relationships, and so gain a bird's-eye view of the entire corporate landscape.

In recent times, the analysis of the types of large and complex networks exemplified by a network of firms has received an enormous amount of attention (see Newman (2003) for an overview). A network is simply a graph in which a set of nodes (or vertices) are linked together by edges. The nodes represent entities of some sort, and the edges indicate the presence of some kind relationship or tie between two nodes. For example, firm networks are constructed by considering firms as nodes, with an edge between firms representing an interlock between those two firms i.e. the presence of one or more common directors on both the boards. From this relatively simple empirical data, a considerable amount of information on the aggregate structure of the system can be derived using the mathematical machinery developed for the analysis of these networks. This kind of network analysis has been used to investigate a diverse array of complex systems, some examples of which are friendships between individuals (Rapoport, 1961), contact between sexual partners (Jones \& Handcock, 2003), co-authorship of scientific papers (Newman, 2001), the structure of the Internet and worldwide web (Barabasi, Albert \& Jeong, 2000), predatorprey relationships in ecological food webs (Montoya, Pimm \& Sole, 2006), the metabolic system of E.coli (Wagner, 2001 ) and the co-occurrences of words in human language (Ferrer i Cancho \& Sole, 2001).

In this paper, we construct and analyse the network describing the current corporate landscape in South Africa. We do this using information on the boards of directors of all publicly-listed companies on the Johannesburg Stock Exchange (JSE) at 1 March 2008. Similar analyses have been conducted for several other countries, specifically the US (Newman, Strogatz \& Watts, 2001, Davis et al., 2003, Conyon \& Muldoon, 2006), UK (Conyon \& Muldoon, 2006), Germany (Conyon \& Muldoon, 2006; Kogut \& 
Belinky, 2008), Switzerland and the Netherlands (Heemskerk \& Schnyder, 2008), and Denmark, Sweden and Norway (Sinani et al., 2008). Our broad aim in this paper is to provide a similar overview of the corporate network for South Africa, an emerging market differing from the more highly-developed economies of the countries mentioned above. In doing so, we show that many of the structural features found for networks in other countries also hold in South Africa, which suggests that these corporate networks may be relatively insensitive to the stages of economic development of a nation.

The paper is structured as follows. The first two sections give an introduction to the analysis of complex networks. A summary of previous research on corporate networks is then provided. We then describe the data set used in the current study, provide the results of the network analysis, and compare the results obtained to those previously found for other countries. A final section offers some conclusions and ideas for future research.

\section{Representing boards of directors with social networks}

A network is a graph in which a set of nodes (or vertices) are linked together by edges. The nodes represent entities of some sort, and the edges indicate the presence of some kind relationship or tie between two nodes. For example, when examining boards of directors the directors themselves can be thought of as nodes in the graph, with an edge existing between two directors if they sit together on the board of the same company. An example of such a "director-centric" network is shown in Figure 1, which shows the network that exists between directors of three of the firms in our current study (from left to right as they appear in Figure 1: Ideco, Simmer and Jack Mines, and First Uranium Corporation). Individuals that sit on more than one board are denoted by black circles.

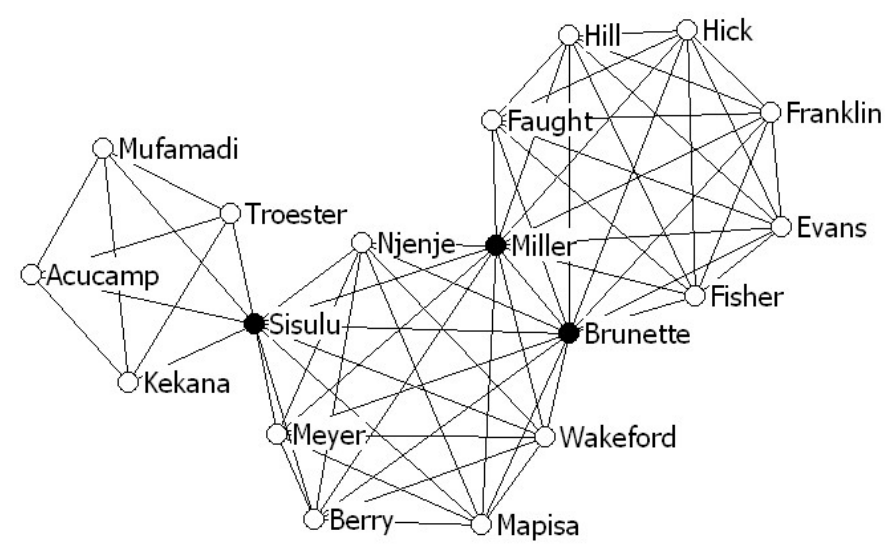

Figure 1: Example of a directorship network

It is also possible to view corporate directorships in a different way, by considering firms to be the nodes of the graph with an edge existing between two firms if they have one or more board members in common. An example of this kind of "firm-centric" network is shown in Figure 2, which shows the network existing between the three firms of Figure 1. Ideco and Simmer and Jack Mines share one director (A Sisulu) and are thus connected, while Simmer and Jack Mines and First Uranium Corporation share two (G Miller and N Brunette) and are thus also connected. Note that there is some loss of information here: the firm-centric network does not distinguish between a pair of firms that shares one director, and a pair that shares more than one director (the same would be true of the director-centric network in Figure 1).

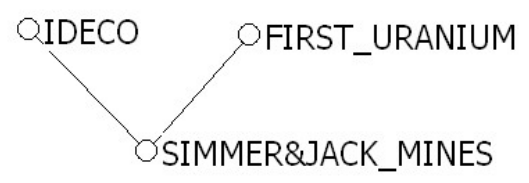

Figure 2: Example of a firm network

The dual representation of the corporate directorship information arises because there are two distinct types of nodes: directors and firms. A more succinct way of representing corporate directorships is to have both director nodes and firm nodes in the same graph, with an edge between a director and a firm if the director is a board member of the firm. Thus, edges can only exist between nodes of different types, never between two directors or two firms. A network of this type is called a bipartite network. The bipartite network for the three-firm example is shown in Figure 3.

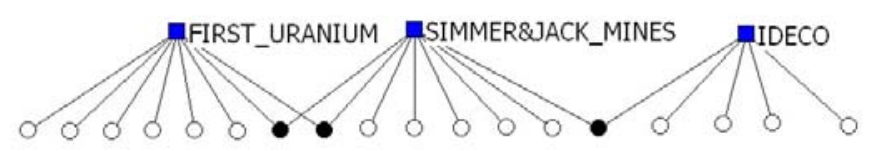

Figure 3: Example of a bipartite network of directors and firms

The bipartite graph shows the full structure of the corporate directorship network. Note that the director-centric and firm-centric networks can be easily obtained from the bipartite graph. For example, by noting that First Uranium Corporation and Simmer and Jack Mines share two directors, a link between those two firms in the firm-centric network can be inferred. Figure 3 also shows that First Uranium Corporation and Ideco have no directors in common - so that there would be no link between the firms in the firm-centric network. Similar observations can be made for relationships between directors. In network terms, Figure 1 shows the projection of the bipartite graph onto the director nodes (or director projection for short), while Figure 2 shows the projection of the bipartite graph onto the firm nodes (or firm projection). In analysing the bipartite graphs representing board membership, it is common to analyse the two projections separately - this is the approach that we take here.

\section{Characterising corporate directorship networks}

Analysing social networks is largely an exercise in finding appropriate ways of representing the most important structural aspects of the network. When analysing networks of directors and firms, the most important structural questions often relate to how well "connected" the network is. This connectedness is typically measured using the following network measures. 


\section{Size of the largest connected component}

A connected component associated with a particular node is the collection of all nodes that can be reached from that node by travelling along edges of the graph. For example, the network in Figure 1 consists of a single connected component since any node can be reached from any other node. Many networks, including the one we shall consider, have more than one connected component. In these cases, the size of the largest connected component in the network is usually given as an indication of the overall connectedness of the network. Nodes that do not form part of the largest connected component are essentially peripheral to any dynamics occurring within the network.

\section{Degree}

The degree of a node is simply the number of edges leaving that node and is therefore an indication of how wellconnected a particular node is. At an aggregate level, the average degree in a network provides an indication of the average number of connections possessed by directors or firms. Because the distribution of degree is usually strongly skewed to the right, especially for the director projection, it is common to examine the full degree distribution in addition to summaries such as the mean.

\section{Distance}

The distance between any two nodes is the smallest number of edges in the graph that must be traversed to reach one node from the other. It represents the length of the shortest path between the two nodes and can also be used as a proxy for how easily information can spread between these nodes (or how easily influence can be wielded, etc). For example, directors separated by a distance of one sit on the same board and are thus in direct contact with one another. Directors that are separated by a distance of two do not sit on the same board themselves, but each sit on their respective boards with a member who is common to both of the boards. They are thus in indirect contact via an intermediary. As for degree, distances can be evaluated by taking the average distance over all pairs of nodes or by examining the full distribution of distances. Where two nodes do not lie in the same connected component, there exists no path between them and the distance between them is undefined. As a result, it is usual when computing the average distance to consider only those nodes that lie in the largest connected component.

\section{Clustering}

A highly-clustered network is one in which a node's neighbours (those nodes to whom it is connected) tend also to be neighbours themselves (to also be connected to one another). Several definitions of the clustering coefficient have been proposed. One idea is to assess the total number of edges that could exist between the neighbours of a particular node. If a node $j$ has degree $d_{j}$ (implying that it has $d_{j}$ neighbours) then there can be at most $d_{j}\left(d_{j}-1\right) / 2$ edges between these $d_{j}$ neighbours. The clustering coefficient of node $j$ is then given by the proportion of these edges that actually do exist in the graph. An overall clustering coefficient can be obtained by averaging the clustering coefficients of all nodes in the network. We refer to this measure, following Conyon and Muldoon (2006), as the Watts-Strogatz clustering measure, after its use in Watts (1999). An alternate definition uses a connected triple as the unit of analysis. A connected triple is a set of three nodes, say $a, b, c$, in which $a$ is connected to $b$ and $b$ is connected to $c$, but $a$ is not necessarily connected to $c$. The proportion of all connected triples in which $a$ in fact is connected to $c$ is defined as the transitivity-based clustering coefficient. For example, the graph in Figure 2 shows a connected triple in which the third link between Ideco and First Uranium Corporation is not present. This graph therefore has a clustering coefficient of 0 , since the only connected triple is not a completed triangle. Director projections (and social networks in general) tend to show high clustering, because the nature of board membership is such that if two people are both connected to a third director, it is probably because all three of them sit on the same board.

\section{Assortativity}

The notion of assortative mixing explores the correlation between certain characteristics of nodes in a network and the same characteristics of the nodes that they are connected to. A simple example is a social network where two nodes are connected if they are married to one another, and the characteristic of interest is a racial demographic. No assortative mixing implies no relationship between the race groups of partners over the whole network, while positive (negative) associative mixing implies that two partners are more (less) likely to belong to the same race group. In the context of this study, we are interested in a particular type of assortativity, one where the characteristic of interest is the degree of the node. Thus, we are interested in whether nodes with high degree tend to be connected to other nodes of high degree, or not. Within corporate directorship networks, the assortativity coefficient is particularly important because it indicates whether "high-flying" directors tend to sit on boards with other "high-flying" directors more than would be expected under a random model.

\section{Small worlds and random networks}

The "small-world" phenomenon is the name given to the discovery of a surprisingly short chain of intermediaries that connects two people who had previously never met. A classic demonstration of the small-world effect was performed by Milgram (1967), who gave subjects a letter together with an instruction to send the letter to a randomlyselected target individual - with the restriction that they could only send the letter on to someone who they knew on a first name basis, who would receive similar instructions. Famously, the letters that did find their way to the target did so in an average of less than six steps.

In network terms, the small-world effect has been defined as a combination of a short average distance and a high degree of clustering. Following this formulation, many types of networks have been discovered to possess small-world characteristics. However, the definition of a small-world 
demands that one provide some kind of basis for comparison i.e. some way of answering the question: "small relative to what?" One approach (e.g. Davis et al., 2003) is to compare the network to a completely random graph where all that is known is the number of director nodes $N$, the number of firm nodes $M$, and the total number of edges in the graph. These are known as Poisson random graphs. A different approach (e.g. Conyon \& Muldoon, 2006) is to compare the network to one which has precisely the same distribution of directorships held and board sizes as in the observed network but in which connections between director nodes and firm nodes occur at random. These networks are known as random graphs with arbitrary degree distributions. Standard formulae are available for the expected values of various network statistics under assumptions of Poisson or arbitrary random degree distributions (e.g. see Conyon \& Muldoon, 2006). What is not always made explicit is that both these comparisons provide valuable information. The former shows whether a network is a "small-world" in the conventional sense of a network possessing a similarly short average distance to a Poisson random graph while having a far larger clustering coefficient. The latter shows whether the "smallness" of the small-world can be entirely explained by the distributions comprising the bipartite graph or whether there is some additional non-random structure that requires explanation. We thus show comparative statistics from both the Poisson random graph and the random graph with arbitrary degree distributions.

\section{Literature review}

Research on corporate networks tends to fall into two broad categories. The older and more well-established of the two examines the causes and consequences of interlocks between firms, viewing the firm as the unit of analysis. This kind of analysis has the advantage that it is not necessary to reconstruct the complete firm network. It is sufficient to identify a firm that shares a common director with another and is thus interlocked, and investigate whether there are any significant antecedents and consequences of this tie. This is often known as 'interlock' research, a label we adopt here. The second type of corporate network research views the complete interlocked network of firms (or directors) as the focus of analysis. Much of this work has considered the statistical properties of these complete networks, although of course given the data it is also possible to conduct some firm- or industry-level analyses, for example identifying firms that have the highest degree or evaluating the assortativity between industries. While many of the papers published in this relatively new area are concerned with whether a network is a 'small world' or not, this is only one of the topics that can be addressed. We thus prefer to label this particular direction research into 'corporate systems', its defining feature being the consideration of the network as a whole.

\section{Interlock research}

Interlock research is focused on what, if anything, causes firms to interlock, and what effects interlocking directorates have for the firms involved. Both these investigations have a strong behavioural component.

\section{Causes of interlocks}

Hypothesised causes of interlocks include attempts at collusion, coopting sources of environmental uncertainty, monitoring, enhancing reputation and legitimacy, the career advancement of the directors involved, and social ties among the elite class (Mizruchi, 1996). While collusion via interlocks between firms in the same industry is effectively prohibited by competition laws, an early study found almost no association between profitability and interlocks with competitors in any case (Pennings, 1980). Moreover, there is no real reason to suggest that interlocks are the most effective means to achieve collusion, given the possibility of detection. There is more evidence to suggest cooptation as a possible source of interlocks (e.g. Thompson \& McEwen, 1959; Burt 1983), but here too there are conflicting views. Most ties broken by the death or retirement of the interlocking director are not re-established (Ornstein, 1980; Palmer, 1983), suggesting cooptation was not a decisive factor in establishing the original relationship (Mizruchi, 1996). Several findings in favour of a monitoring explanation have been made, in particular those finding an increased likelihood of unprofitable firms forming interlocks (e.g. Dooley, 1969; Mizruchi \& Stearns, 1988), especially with banks (Richardson, 1987; Mizruchi \& Stearns, 1988). As pointed out by Mizruchi (1996), cooptation and monitoring both result from resource dependencies and are thus difficult to separate empirically.

The other explanations stated above focus on the characteristics of the directors forming interlocks rather than the firms themselves. Directors signal the reputation of the firm on whose board they sit (e.g. Selznick, 1984), and individuals are thus often chosen on the basis of their own reputation (Mace, 1971; Useem, 1984). As a consequence, directors are more likely to be nominated to new boards if they are already a member of several boards (Davis, 1993). Of course, both legitimacy and reputation explanations require that the potential directors be known in the first place, and this is far more likely to occur with a given (upper) social stratum. This feature has been noted by several researchers (e.g. Zeitlin, 1974; Useem, 1984) as effective 'elements of capital class integration' (Mizruchi, 1996).

In summary, with the exception of collusion, there exists some evidence in favour of all of the hypothesised causes for interlocks to form, but this evidence tends to vary from study to study. A sensible appraisal of this body of knowledge might therefore be that the above factors are by no means mutually exclusive, and that any of them can influence a decision to interlock at one time or another, either individually or in combination with one another. 


\section{Consequences of interlocks}

Research into the effects of interlocks on firm behaviour has yielded numerous and varied results. Mizruchi (1996) gives a summary of these, while Davis et al., (2003) and Di Pietra et al. (2008) present the more recent evidence. Interlocking directorates have been shown to facilitate the adoption of executive compensation practices such as "golden parachutes" (Cochran, Wood \& Jones, 1985), "greenmail” (Kosnik, 1987), and "poison pills" (Davis, 1991; Davis \& Greve, 1997). Others have found that the amount of external financing a firm receives is related to bank representation on its board (Mizruchi \& Stearns, 1994), and that a relationship between interlocks and contributions to political candidates as well as congressional testimony exists (Mizruchi, 1992). Interlocks also serve to facilitate switching behaviour between stock exchanges: Nasdaq-listed firms were more likely to switch to the New York Stock Exchange if the firms with whom they were interlocked had previously done so (Rao, Davis \& Ward, 2000). As Davis et al. (2003) put it, "board interlocks may be a fortuitous by-product of board preferences for recruiting experienced directors, with little strategic intent ... yet the result is the creation of a network that is highly consequential for board decision-making”.

Interlocks also have an effect on the directors involved in them. Interlocked directors tend to be less effective at monitoring (Fich \& Shivdasani, 2006) and more likely to be absent from board meetings (Jiraporn, 2007). Moreover, interlocks also seemingly exert some influence over investors: Di Pietra et al. (2008) find that in Italy, the number of additional directorships held by a board of directors (expressed as a proportion of board size) has a positive association with the market value of a firm.

\section{Research into corporate systems}

Following Watts and Strogatz's (1998) work on 'small world' networks (see Watts (2003) or Barabasi (2003) for popular introductions), similar analyses were soon applied to directorship networks, first as part of a theoretical paper (Newman, Strogatz \& Watts, 2001) and later as several fulllength articles (e.g. Davis et al., 2003; Conyon \& Muldoon 2006). The focus of these papers is on quantifying the structure of the directorship network in its entirety, in terms of the network statistics identified previously. Particular attention has been paid to clustering coefficients and geodesic distances, which when large and small respectively signal that the network is a 'small world'. Table 1 summarises previous research into the shape of director and firm networks in terms of the three key statistical properties discussed earlier: average degree, distance and clustering.

Results differ widely over the studies. Average firm degree varies between 1,1 and 23,8; average distance between 1,8 and 5,1; clustering coefficients of the Watts-Strogatz variety between 0,22 and 0,71; and clustering coefficients based on transitivity between 0,17 and 0,73. However, direct comparisons are complicated by different choices regarding sample design and analysis. These can be summarised as (a) whether to use all publicly traded firms or a subset of these firms, usually containing the largest $N$ firms, (b) whether to restrict attention to the largest connected component or not, (c) whether to compare the empirical network to a Poisson or arbitrary random graph. These choices are often dictated by the aims of a particular piece of research. The studies that most closely resemble our own are those of Conyon and Muldoon (2006).

\section{Data}

The network that we investigate comprises the boards of directors of all JSE-listed South African companies as at 1 March 2008. This information was obtained from the McGregor BFA database and checked manually for consistency. One problem that arises is that companies may provide different levels of detail in the names of their directors, for example in the number of initials that are specified. Our approach has been to correct only obvious errors and omissions (for example, NJM Canca and NJMG Canca are presumably the same person). The resulting dataset contains 2747 directors and 397 firms.

\section{Results}

We begin by giving a broad overview of the current state of corporate directorship in South Africa, aided by the descriptive statistics in Table 2, which are given both for the full network and the largest connected component although in the following we primarily report the results from the full network.

The average number of directors sitting on the board of a JSE-listed company is 8,56, ranging greatly from just two directors to 27. This mean board size is between the values reported by Conyon and Muldoon (2006) for the USA $(9,97$ members) and the UK (6,51 members) and Germany $(6,33$ members). The full distribution of board sizes is shown in Figure 4(b), which shows a distribution that is somewhat but not greatly skewed to the right - the coefficient of skewness is 1,1 but the median board size is eight, very close to the mean. The average number of directorships held is 1,28 , and the overwhelming majority of directors (83\%) are members of just a single board. This average number of directorships held in South Africa is marginally lower than those reported by Conyon and Muldoon for the USA (1,63 directorships), UK (1,84 memberships) or Germany (1,45 memberships), but the proportion of single-board directors matches closely. This suggests that differences exist predominantly in the right-tail, perhaps due to the larger numbers of firms occupying those markets. Figure 4(a) shows the full distribution of directorships held, but here frequencies are shown on a logarithmic scale because the distribution is so right-skewed (the coefficient of skewness is 4,1 and the median is of course one). There are just 32 directors $(1,2 \%)$ who hold five or more board memberships - in the absence of logarithmic scaling, this detail in the right-tail is impossible to distinguish. 
Table 1: Summary of previous research analysing the statistical properties of firm and director networks. The table shows the average degree $z$, average geodesic distance $L$, and two clustering measures (the transitivity-based $c_{t}$ and the Watts-Strogatz clustering measure $c_{W S}$ ), for both the firm- and director-projections, where available. The final two columns indicate whether the full set of publicly-listed firms was used or a subset of 'largest' firms, and whether the analysis was restricted to the largest component only

\begin{tabular}{|c|c|c|c|c|c|c|c|c|c|c|c|c|c|c|}
\hline & & & & & & Firm & ection & & & irecto & ojection & & & \\
\hline Country & Year & Reference & Firms & Dirs & $z$ & $L$ & $C_{t}$ & $C_{W S}$ & $z$ & $L$ & $C_{t}$ & $C_{W S}$ & $\begin{array}{c}\text { Full } \\
\text { network? }\end{array}$ & $\begin{array}{c}\text { Largest } \\
\text { comp } \\
\text { used? }\end{array}$ \\
\hline Denmark & 1993 & Kogut and Belinky (2008) & 313 & & 23,8 & 2,5 & & 0,73 & & & & & Unclear & No \\
\hline Denmark & 2000 & Sinani et al (2008) & 155 & 1129 & 3,1 & 5,1 & 0,51 & & 11,3 & 5,9 & 0,93 & & No & Yes \\
\hline Denmark & 2003 & Kogut and Belinky (2008) & 534 & & 2,7 & 3,7 & & 0,54 & & & & & Unclear & No \\
\hline Germany & 1993 & Kogut and Belinky (2008) & 304 & & 7,5 & 2,6 & & 0,39 & & & & & Unclear & No \\
\hline Germany & 2000 & Kogut and Belinky (2008) & 630 & & 7,8 & 2,9 & & 0,38 & & & & & Unclear & No \\
\hline Germany & 2002 & Conyon and Muldoon (2006) & 582 & 4185 & 4,6 & 2,9 & 0,41 & 0,58 & 14,5 & 6,4 & 0,93 & 0,72 & Yes & Yes \\
\hline Netherlands & 1996 & Heemskerk and Schnyder (2008) & 194 & 1771 & 8,0 & 3,0 & 0,38 & & 12,8 & 3,8 & & & No & Yes \\
\hline Netherlands & 1997 & Kogut and Belinky (2008) & 1152 & & 3,8 & 4,0 & & 0,56 & & & & & Unclear & No \\
\hline Netherlands & 2001 & Heemskerk and Schnyder (2008) & 137 & 1721 & 7,0 & 3,2 & 0,35 & & 11,4 & 3,9 & & & No & Yes \\
\hline Netherlands & 2001 & Kogut and Belinky (2008) & 2253 & & 2,4 & 3,3 & & 0,63 & & & & & Unclear & No \\
\hline Norway & 1990 & Kogut and Belinky (2008) & 53 & & 1,4 & 4,2 & & 0,48 & & & & & Unclear & No \\
\hline Norway & 2000 & Sinani et al (2008) & 23 & 78 & 3,5 & 3,6 & 0,71 & & 7,7 & 3,1 & 0,92 & & No & Yes \\
\hline Norway & 2000 & Kogut and Belinky (2008) & 301 & & 1,1 & 1,8 & & 0,72 & & & & & Unclear & No \\
\hline Sweden & 1990 & Kogut and Belinky (2008) & 229 & & 5,0 & 3,0 & & 0,42 & & & & & Unclear & No \\
\hline Sweden & 2000 & Sinani et al (2008) & 265 & 1457 & 5,3 & 4,0 & 0,40 & & 14,6 & 4,8 & 0,88 & & Yes & Yes \\
\hline Sweden & 2000 & Kogut and Belinky (2008) & 352 & & 3,1 & 3,7 & & 0,43 & & & & & Unclear & No \\
\hline Switzerland & 1990 & Heemskerk and Schnyder (2008) & 96 & 888 & 8,2 & 2,6 & 0,40 & & 17,8 & 3,4 & & & No & Yes \\
\hline Switzerland & 1990 & Kogut and Belinky (2008) & 96 & & 4,1 & 2,6 & & 0,41 & & & & & Unclear & No \\
\hline Switzerland & 2000 & Heemskerk and Schnyder (2008) & 95 & 848 & 4,4 & 3,8 & 0,42 & & 14,2 & 4,8 & & & No & Yes \\
\hline Switzerland & 2000 & Kogut and Belinky (2008) & 238 & & 2,4 & 4,0 & & 0,52 & & & & & Unclear & No \\
\hline UK & 2002 & Conyon and Muldoon (2006) & 1732 & 8850 & 5,7 & 4,1 & 0,38 & 0,38 & 9,0 & 6,5 & 0,89 & 0,61 & Yes & Yes \\
\hline USA & 1982 & Davis, Yoo and Baker (2003) & 581 & 5853 & 10,0 & 3,4 & 0,24 & & 19,0 & 4,3 & 0,88 & & No & Yes \\
\hline USA & 1990 & Davis, Yoo and Baker (2003) & 524 & 4768 & 8,8 & 3,5 & 0,24 & & 17,0 & 4,3 & 0,87 & & No & Yes \\
\hline USA & 1999 & Newman, Strogatz and Watts (2001) & 914 & 7673 & & & & & 14,4 & 4,6 & 0,88 & 0,59 & No & No \\
\hline USA & 1999 & Davis, Yoo and Baker (2003) & 516 & 4538 & 8,6 & 3,5 & 0,22 & & 16,0 & 4,3 & 0,87 & & No & Yes \\
\hline USA & 2003 & Conyon and Muldoon (2006) & 1473 & 11057 & 7,3 & 3,5 & 0,23 & 0,17 & 13,5 & 5,2 & 0,87 & 0,56 & Yes & Yes \\
\hline
\end{tabular}

Table 2: Descriptive statistics on the profile of corporate directorship in South Africa (all means given with associated standard errors in parentheses)

\begin{tabular}{lcr}
\hline & Full network & Largest connected component \\
\hline Director seats & 3398 & 2764 \\
\hline Number of unique directors & 2653 & 2048 \\
\hline Number of firms & 397 & 294 \\
\hline Average board size & $8,56(0,19)$ & $9,40(0,22)$ \\
\hline Maximum board size & 27 & 27 \\
\hline Minimum board size & 2 & 4 \\
\hline Average number of directorships & $1,28(0,02)$ & $1,35(0,02)$ \\
\hline Maximum number of directorships & 9 & 9 \\
\hline One-board director (\%) & $83 \%$ & $79 \%$ \\
\hline Two-board director (\%) & $11 \%$ & $13 \%$ \\
\hline
\end{tabular}



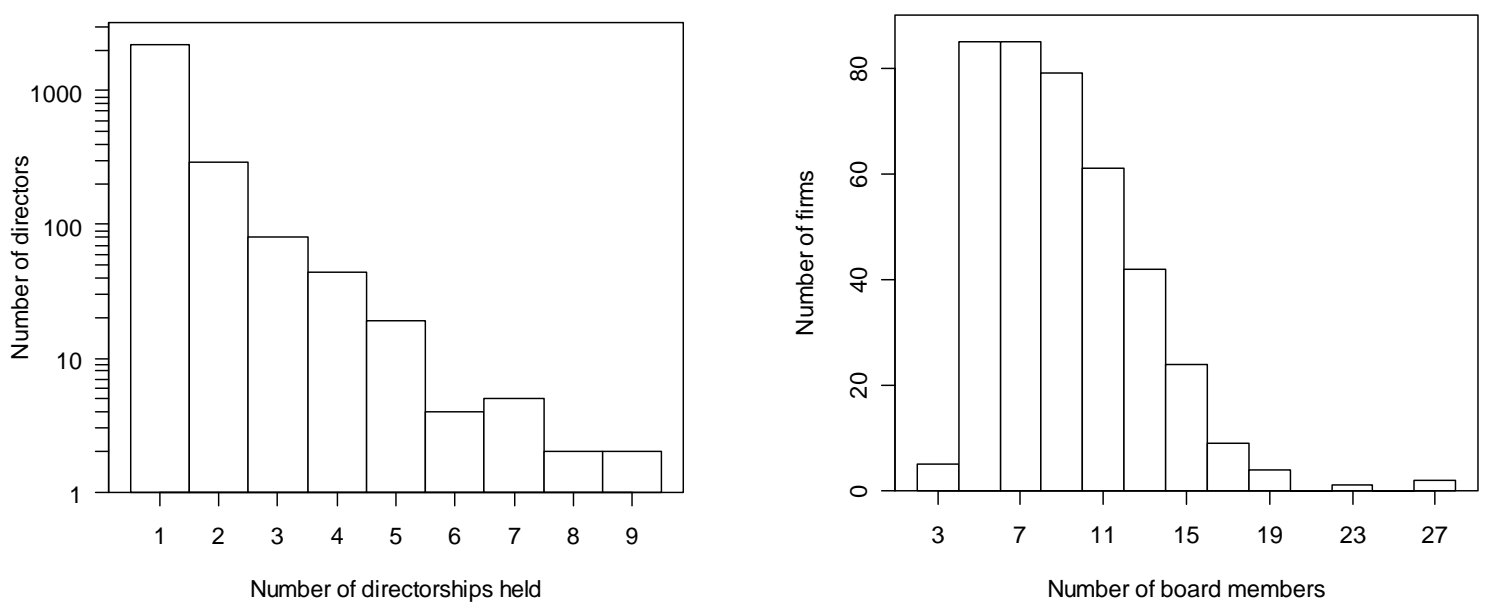

Figure 4: Histograms showing the distribution of (a) the number of directorships held, and (b) the number of members per board. Note that the former is measured on a logarithmic scale because it is extremely right-skewed.

Having examined these basic statistics, we now turn to a more detailed analysis of the structure of the corporate directorship network. Table 3 shows the sizes of the two largest components in the director- and firm-projections of the directorship network. The degree of connectivity exhibited in both the director and firm networks is fairly high - roughly three-quarters of all directors and all firms are connected by some path. A similar level of connectivity was reported by Conyon and Muldoon (2006) for the United Kingdom, with slightly higher connectivity reported for the USA.

Table 3: Absolute and relative sizes of the two largest components in the director- and firm-projections

\begin{tabular}{lc}
\hline Largest connected component - firms & $294(74 \%)$ \\
\hline 2nd largest connected component - firms & $6(2 \%)$ \\
\hline Largest connected component - directors & $2048(77 \%)$ \\
\hline 2nd largest connected component - directors & $20(1 \%)$ \\
\hline
\end{tabular}

Table 4 and 5 show the most important of the network statistics: the average degree, distance, clustering coefficient, and the assortativity coefficient, for the full networks and for the largest connected component respectively. Also presented in these tables are values for these quantities that would be expected under different types of random network models. The two network models used are those discussed earlier in the section "Small worlds and random networks". The Poisson random graph results show what quantities would be expected if only the total number of connections was constrained, but the distribution of connections as well as how those connections are formed were allowed to be random. These results are largely of interest because they allow one to infer whether a network is a "small-world" or not - the conventional definition of a small-world network being one that has a similar average distance to a Poisson random graph while having a much larger clustering coefficient. The random graph with arbitrary degree distribution shows what would be expected if the entire distribution of directorships and boards were fixed (i.e. at those shown in Figure 4(a) and (b)) and only the connection of firms to directors was at random. These expected values can be used to infer whether there is any additional structure that is not accounted for by a "smallworld” network model.

The average director in South Africa shares a board with just over 11 other directors. That is, they are in direct contact with some 11 people. If attention is restricted to the largest connected component, this figure rises to almost 13. This increase occurs because the firms outside the largest component have on average both smaller boards (MannWhitney $Z=8,4, p<0,001$ ) and fewer interlocks with other companies (Mann-Whitney $Z=14,1, p<0,001$ ). The average distance between two directors in the network is just 4,3 . The smallness of this figure is no less remarkable for the fact that it has been observed in so many networks: in a network of over 2500 directors, two directors can be connected using a path consisting of just three intermediate directors. The network is also highly clustered relative to what would expect from a purely random Poisson graph. The high degree of clustering relative to a Poisson random graph together with this short average distance is a hallmark of the "small-world" network. It is therefore clear that the network of corporate directors in South Africa can be described as a small world. 
Table 4: Network statistics for the director- and firm-projections, with statistics that would be expected from random graphs with the same distributions of directorships and board sizes but random connections (ArbDD), and from completely random graphs (Poisson). All observed means given with associated standard errors.

\begin{tabular}{lcccccc}
\hline & \multicolumn{3}{c}{ DIRECTORS } & & \multicolumn{2}{c}{ FIRMS } \\
\hline & Observed & ArbDD & Poisson & Observed & ArbDD & Poisson \\
\hline Degree & $11,397 \pm 0,181$ & 11,737 & 11,397 & $5,234 \pm 0,293$ & 6,470 & 5,234 \\
\hline Distance & $4,312 \pm 0,024$ & 3,801 & 3,240 & $3,654 \pm 0,061$ & 3,127 & 3,615 \\
\hline Clustering (trans.) & $0,573 \pm 0,006$ & 0,593 & 0,004 & $0,293 \pm 0,008$ & 0,248 & 0,013 \\
\hline Clustering (W-S) & $0,916 \pm 0,004$ & - & - & $0,266 \pm 0,016$ & - & - \\
\hline Assortativity & $0,256 \pm 0,008$ & 0,115 & 0 & $0,245 \pm 0,029$ & 0,131 & 0 \\
\hline
\end{tabular}

Table 5: Network statistics for the largest connected components of the director- and firm-projections, with statistics that would be expected from random graphs with the same distributions of directorships and board sizes but random connections (ArbDD), and from completely random graphs (Poisson). All observed means given with associated standard errors.

\begin{tabular}{lcccccc}
\hline & \multicolumn{3}{c}{ DIRECTORS } & & \multicolumn{2}{c}{ FIRMS } \\
\hline & Observed & ArbDD & Poisson & Observed & ArbDD & Poisson \\
\hline Degree & $12,923 \pm 0,220$ & 13,342 & 12,923 & $6,918 \pm 0,344$ & 8,501 & 6,918 \\
\hline Distance & $4,312 \pm 0,024$ & 3,298 & 2,980 & $3,654 \pm 0,061$ & 2,618 & 3,942 \\
\hline Clustering (trans.) & $0,555 \pm 0,006$ & 0,544 & 0,006 & $0,291 \pm 0,009$ & 0,207 & 0,024 \\
\hline Clustering (W-S) & $0,896 \pm 0,005$ & - & - & $0,332 \pm 0,018$ & - & - \\
\hline Assortativity & $0,195 \pm 0,008$ & 0,088 & 0 & $0,219 \pm 0,028$ & 0,105 & 0 \\
\hline
\end{tabular}

A social network will, except in pathological cases, exhibit small-world characteristics as a result of its structure i.e. individuals belong to groups, so that non-trivial clustering is almost always present, and group sizes differ, inducing correlations between the degrees of adjacent nodes (Newman \& Park, 2003). Thus the identification of a corporate directorship network as a small-world is on one hand interesting and on the other entirely expected. This is reflected in the strong agreement between the observed values and the expected values for a random graph with arbitrary degree distributions, for the average degree and clustering. The similarity exists to a lesser extent for the average distance, although even here the figures remain in rough agreement. All these findings are in substantive agreement with those reported by Conyon and Muldoon (2006) and Sinani et al. (2008). In those studies, average degrees varied between 9,0 for the UK and 14,6 for Sweden; distances ranged from 4,8 in Sweden to 6,5 in the UK; and (transitivity-based) clustering coefficients differed from 0,56 in the USA to 0,72 in Germany. The values we observe in South Africa are similar, and the degree and clustering statistics (regardless of whether the transitivity-based or Watts-Strogatz clustering is used) fall within these intervals. The average distance is slightly lower than that reported by Conyon and Muldoon (2006), but this may at least in part be due to the smaller network studied here. Furthermore, the closeness of match between observed and expected degrees and clustering, as well as the slightly longer-than-expected average distance, were also all reported by Conyon and Muldoon (2006). Sinani et al. (2008) use the Poisson random model as a basis for comparison, and thus differences between their expected and actual results are not directly comparable with ours.
Thus the South African corporate landscape is a smallworld, and is of a similar structure to the previously studied countries, in particular the USA and UK. What is far less obvious is whether there is any additional structure beyond the small-world that remains. In respect to this, the assortativity coefficient plays a key role. As mentioned, positive assortativity is to be expected in most social networks, and given the particular distributions of board sizes and directorships in South Africa, the expected assortativity is 0,12 . This makes the observed assortativity coefficient of 0,26 in Table 3 of special interest. The presence of typical social network structures (essentially, groups of different sizes) is only sufficient to explain about $40 \%$ of the correlation that is observed. Newman and Park (2003) find almost precisely the same results (an assortativity coefficient of 0,28 against an expected value of 0,12) for firms in the USA. Conyon and Muldoon (2006) also find positive assortativity, but do not compare it to any benchmark. It is thus difficult to draw a comparison with their study, but it is fairly clear that there is additional structure in corporate directorship networks, and that this effect is present in South Africa too. Note that the absolute assortativity is lower in the largest connected component because most directors outside the main component will tend to have relatively few connections, and will thus tend to be connected to other directors of similarly low degree. Nevertheless, the same substantive finding - that this assortativity is well beyond what one would expect from a random graph - still holds. One intuitively attractive explanation that has been put forward by Newman, Strogatz and Watts (2001) is that directors who sit on many boards tend to sit on those boards with directors who themselves sit on many boards. This effect has been called the "homophily 
effect” (e.g. McPherson, Smith-Lovin \& Cook, 2001) or more colloquially "like goes with like".

We turn briefly now to the other projection, of boards, and note that most of the important conclusions drawn in the previous discussion of the directorship-projection apply here too. To a large extent that is simply a consequence of the bipartite nature of the graph. A JSE-listed company is directly connected to an average of 5,2 other companies, although this increases 6,9 if only the largest component is considered. These are somewhat lower figures than those expected under a random graph model with the same board size and directorship distributions, but the differences are comparable in magnitude to the one noted by Conyon and Muldoon (2006) for firms in the USA, and is not as large as differences noted by the same authors for firms in UK and Germany. The average distance connecting two firms is again remarkably short, just 3,6, which together with the moderate amount of clustering confirms the expected smallworld effect in this projection too. The assortativity coefficient is as expected positive, but considerably more so than would be predicted by any graph using purely random connections. The connections formed in a corporate directorship therefore exhibit some non-random behaviour, probably some form of homophily.

The full distributions of director degrees and firm degrees are shown in Figure 5(a) and (b) respectively. Here we have elected to show the cumulative distributions, which show the same pattern as the marginal distributions but avoid the fairly arbitrary specification of a bin width, and again we use a logarithmic scale because of the right-skewness in both degree distributions. The distribution of director degrees brings into sharp relief that although the average number of director connections is just over 11, there are some directors who are in direct contact with far more other directors than this. There are 28 directors (1\%) who are in contact with 50 or more other directors, up to a maximum of 93. These directors are the glue that holds the corporate directorship network, or at least the largest connected component of this network, together. The distribution of firm degrees is also highly skewed to the right, albeit not to the same extent as the distribution of director degrees (the coefficient of skewness in the distribution of firm degrees is 1,7 ; for director degrees it is 3,3 ). While the average number of firm connections is 5,2, there are some 30 firms (8\%) that are directly connected to 20 or more other firms by virtue of the fact that they share a common board member. The firms with the ten highest degrees are shown in Table 6. It is worth mentioning that firms with a degree of 30 or higher share a board member with nearly $8 \%$ of all firms on the JSE. This clearly puts them in a position of considerable standing within the community of firms. There are three such companies in the dataset (with their respective degrees given in parentheses): Sun International (33), Standard Bank (32), and Mutual and Federal (30).

Table 6: The ten most highly-connected firms in South Africa. The degree of a firm indicates the number of other firms that it shares one or more board members with.

\begin{tabular}{lccc}
\hline Firm & Degree & Board size & Sector \\
\hline SUN INTERNATIONAL & 33 & 15 & Travel \& Leisure \\
\hline STANDARD BANK GROUP & 32 & 18 & Banks \\
\hline MUTUAL AND FEDERAL & 30 & 17 & Nonlife Insurance \\
\hline BIDVEST & 24 & 26 & Support Services \\
\hline IMPERIAL HOLDINGS & 24 & 22 & Banks \\
\hline ABSA GROUP & 24 & 27 & Banks \\
\hline ILLOVO SUGAR & 24 & 16 & Food Producers \\
\hline FIRSTRAND & 23 & 17 & Banks \\
\hline ASPEN PHARMACARE HOLDINGS & 22 & 11 & Pharmaceuticals \\
\hline SANLAM & 21 & 18 & Life Insurance \\
\hline
\end{tabular}

One can see from Figure 5(a) that the director degree distribution predicted by a random graph with an arbitrary degree distribution is an excellent match for the observed director degree distribution. Even in the right-tail of the distribution, there is extremely little divergence between the observed and expected distributions. The Poisson graph model, on the other hand, is shown to be totally inappropriate as a model of corporate directorships. The fit between the observed distribution of firm degree and the distribution expected from a random graph with arbitrary degree distributions, shown in Figure 5(b), is less impressive, and there is some divergence between the distributions both in the left and right tails. Specifically, there are fewer than expected firms with low degrees and a greater than expected number of firms that are highly connected. This is particularly clear in the right-tail of the distribution because of the logarithmic scaling of the frequencies. In plainer terms, this suggests that the reason for the associative mixing is not necessarily so much that directors with high degree sit on the same boards as other high-degree directors, but that firms with high degree tend to be connected to other firms that also have high degree. 

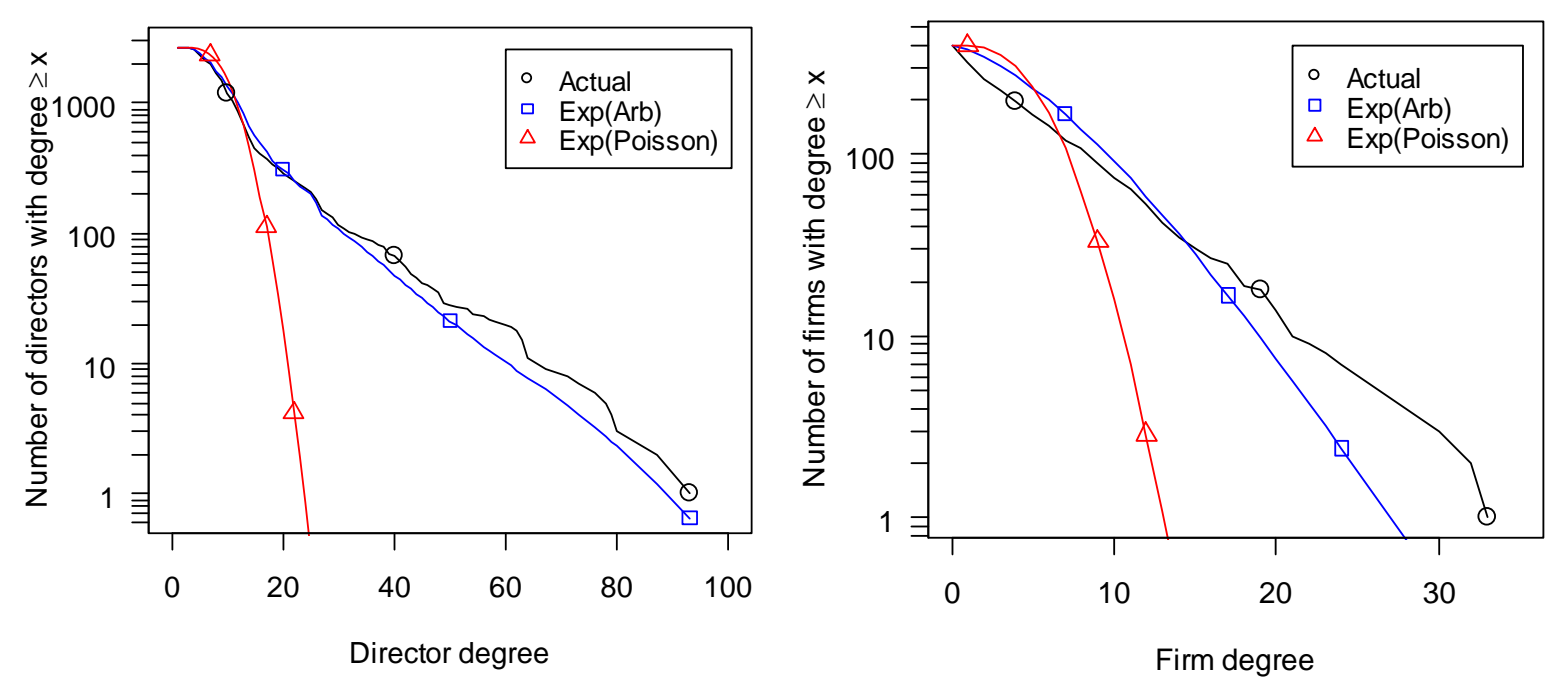

Figure 5: Degree distributions for the nodes in (a) the director-projection and (b) the firm-projection. Both of the distributions are cumulative distributions with frequencies plotted on a logarithmic scale.

\section{Conclusions}

In this paper we have conducted an analysis of the network of publicly-listed firms in the relatively small emerging market of South Africa. The network, properly viewed, is a bipartite one: entities of one type, the directors, are associated with entities of a second type, company boards. From this bipartite structure, we can form two projections: a director network, in which only director nodes are present and an edge between two directors indicates that they sit together on a common board; and a firm network, in which only firm nodes are present and an edge indicates that the two firms involved share one or more directors.

Analyses of these two network projections are becoming increasingly popular, with a special issue of European Management Review (vol. 5, 2008) recently devoted to the topic. Nevertheless there remains much that is idiosyncratic about individual analyses, often linked to sample design, which limits comparisons across studies. In this paper, we identified two such features: the use of a fairly arbitrary proportion of the largest firms in a country, and the restriction of the analysis to the largest component only. Thus, only the results of Conyon and Muldoon (2006) and some of those in Sinani et al. (2008) are directly comparable to our own, which are obtained from all companies listed on the Johannesburg Stock Exchange (JSE) at March 2008. As more network analyses are done, it seems important to attempt to systematise the way analyses are done, to maximise the extent to which these valuable comparisons can be made.

The average company on the JSE is connected to 5,2 others in the company network, and the average South African director connected to 11,4 others. This is roughly comparable with results reported by Conyon and Muldoon (2006) for the US, UK and Germany, and by Sinani et al. (2008) for Sweden. The average distance separating two randomly-chosen directors in South Africa is 4,3; the equivalent distance separating two firms is 3,6 . Both these distances are slightly less than those reported in the other comparable studies, although this is at least partly due to the smaller network in South Africa. Clustering coefficients (based on transitivity rather than the Watts-Strogatz calculations) are 0,57 for directors and 0,29 for firms again, largely consistent with other countries. All of these other networks are from highly-developed economies, considerably more so than the South African one studied here. There appears to be a good indication that the South African network is substantively similar to those of more developed economies. This might indicate that the structure of corporate networks is relatively robust to the stages of a country's development, although of course one would need to conduct analyses on other emerging economies before arriving at any conclusion.

A topic that has been of considerable interest to corporate network researchers has been whether a particular network is a 'small world'. Such interest is deserved because smallworld networks possess a number of properties that are desirable for a corporate system: firstly, information is able to spread quickly and efficiently through the network; secondly, the network as a whole is resistant to the random deletion of nodes. However, much of the small-world research fails to take into account the fact that there are actually three types of 'smallness' - a network can be (a) no smaller than a random network (with Poisson degree distribution), (b) smaller than a Poisson random network but no smaller than a random network with the same-asobserved firm and director degree distributions, or (c) smaller than a random network with the same-as-observed firm and director degree distributions. Bipartite networks, by their very structure, will almost exclusively be of the second or third type. Certainly, there have been no counterexamples in the corporate network literature. The real question of interest therefore is whether networks are of type (b) or (c). We find that clustering in the South African firm network is slightly higher than would be expected using a network with the same degree distributions but random connections; clustering in the director network is extremely similar to what would be expected. However, average distances in both the director and firm network are actually somewhat longer than one would expect from the same-asobserved distributions model. Any additional structure 
therefore seems to firstly, exert a fairly small influence over the properties of the network; and secondly, work to make the network less of a small world, not more. In the final analysis, we would make the claim that the South African director and firm networks are both of the second type i.e. they are small, but are not meaningfully different than one would expect given the degree distributions.

One place where some additional structure (over and above the bipartite nature of the network) does present itself is in the assortative mixing of directors and firms by degree. We find that nodes (be they directors or firms) of high degree are more likely to be connected to other nodes of high degree than would be expected from a random model, even using the same degree distributions. This 'homophily' or the propensity for like to attract like has been previously observed in the US (Newman \& Park, 2003) and UK (Conyon \& Muldoon, 2006). Both our observed and theoretical results are extremely close to those of Newman and Park (2003). This too suggests that homophily may be a general feature of corporate networks, and relatively robust to the stages of economic development.

In considering directions for future research, one realises that there remains much work to be done in this area. Firstly, changes in the structure of corporate networks over time have only begun to be studied (two examples are Davis et al., 2003 and Kogut \& Belinky, 2008), but typically as snapshots rather than using any time series modelling. Secondly, the relating of changes in these networks over time to changes in business practice or financial indicators (both at a firm level and at a system level) is perhaps the critical test for corporate network research. Finally, a systematic study of the effects of different sampling frames on network properties, given the differences between prior studies in this regard, also seems worthwhile.

\section{References}

Barabasi, A. 2003. Linked: How everything is connected to everything else and what it means for business, science, and everyday life. Cambridge: Plume Books.

Barabasi, A., Albert, R. \& Jeong, H. 2000. 'Scale-free characteristics of random networks: the topology of the world-wide web', Physica A: Statistical Mechanics and its Applications, 281: 69-77.

Burt, R. 1983. Corporate profits and cooptation. New York: Academic Press.

Cochran, P., Wood, R. \& Jones, T. 1985. 'The composition of boards of directors and incidence of golden parachutes', Academy of Management Journal 28(3):664-671.

Conyon, M. \& Muldoon, M. 2006. 'The small world of corporate boards', Journal of Business Finance \& Accounting, 33(9-10):1321-1343.

Davis, G. 1991. 'Agents without principles? The spread of the poison pill through the intercorporate network', Administrative Science Quarterly, 36: 583-613.
Davis, G. 1993. 'Who gets ahead in the market for corporate directors: the political economy of multiple board memberships'. In Academy of Management Best Papers Proceedings, 1993. New York, Academy of Management. pp 202-206.

Davis, G. \& Greve, H. 1997. 'Corporate elite networks and governance changes in the 1980s', American Journal of Sociology, 103(1): 1-37.

Davis, G., Yoo, M. \& Baker, W. 2003. 'The small world of the American corporate elite, 1982-2001', Strategic Organization, 1(3):301-326.

Di Pietra, R., Grambovas, C., Raonic, I. \& Riccaboni, A. 2008. 'The effects of board size and 'busy' directors on the market value of Italian companies', Journal of Management \& Governance, 12:73-91.

Dooley, P. 1969. ' The interlocking directorate', American Economic Review, 59(3): 314-323.

Heemskerk, E. \& Schnyder, G. 2008. 'Small states, international pressures, and interlocking directorates: the cases of Switzerland and the Netherlands', European Management Review, 5(1):41-54.

Ferrer i Cancho, R. \& Sole, R. 2001 'The small world of human language', Proceedings of the Royal Society B: Biological Sciences, 268: 2261-2265.

Fich, E. \& Shivdasani, A. 2006. 'Are busy boards effective monitors?', Journal of Finance, LXI(2): 689-724.

Jiraporn, P. 2007. 'Too busy to show up? An analysis of directors' absences'. Great Valley School of Graduate Professional Studies Working Paper.

Jones, J. \& Handcock, M. 2003. 'An assessment of preferential attachment as a mechanism for human sexual network formation', Proceedings of the Royal Society, B: Biological Sciences, 270:1123-1128.

Kogut, B. \& Belinky, M. 2008 'Comparing small world statistics over time and across countries: An introduction to the special issue comparative and transnational corporate networks', European Management Review, 5(1):1-10.

Kosnik, R. 1987. 'Greenmail: a study of board performance in corporate governance', Administrative Science Quarterly, 32:163-185.

Mace, M. 1971. Directors: Myth and reality. Boston, MA: Harvard Business School Press.

McPherson, M., Smith-Lovin, L. \& Cook, J. 2001. 'Birds of a feather: Homophily in social networks', Annual Review of Sociology, 27(1):415-444.

Milgram, S. 1967. 'The small world problem', Psychology Today 2(1): 60-67. 
Mizruchi, M. 1992. The structure of corporate political action. Cambridge: Harvard University Press.

Mizruchi, M. 1996. 'What do interlocks do? An analysis, critique, and assessment of research on interlocking directorates', Annual Review of Sociology, 22(1): 271-298.

Mizruchi, M. \& Stearns, L. 1988. 'A longitudinal study of the formation of interlocking directorates', Administrative Science Quarterly, 33: 194-210.

Mizruchi, M . \& Stearns, L. 1994. 'A longitudinal study of borrowing by large American corporations', Administrative Science Quarterly, 39: 118-140.

Montoya, J., Pimm, S. \& Sole, R. 2006. 'Ecological networks and their fragility’, Nature, 442: 259-264.

Newman, M. 2001. 'The structure of scientific collaboration networks', Proceedings of the National Academy of Sciences, 98(2): 404-409.

Newman, M. 2003. 'The structure and function of complex networks', SIAM Review, 45: 167-256.

Newman, M. \& Park, J. 2003. 'Why social networks are different from other types of networks', Physical Review E, 68(3): 36122.

Newman, M., Strogatz, S. \& Watts, D. 2001. 'Random graphs with arbitrary degree distributions and their applications', Physical Review E , 64(2): 26118.

Ornstein, M. 1980. 'Assessing the meaning of corporate interlocks: Canadian evidence', Social Science Research, 9: 287-306.

Palmer, D. 1983. 'Broken ties: Interlocking directorates and intercorporate coordination', Administrative Science Quarterly, 28: 40-55.

Pennings, J. 1980. 'Interlocking directorates'. San Fransisco: Jossey-Bass.

Rao, H., Davis, G. \& Ward, A.2000. 'Embeddedness, social identity and mobility: Why firms leave the NASDAQ and join the New York Stock Exchange', Administrative Science Quarterly, 45:268-292.

Rapoport, A. \& Horvath, W. 1961. 'A study of a large sociogram', Behavioural Science, 6:279-291.

Richardson, R. 1987. 'Directorship interlocks and corporate profitability’, Administrative Science Quarterly, 32: 367386.

Selznick, P. 1984. Leadership in administration: A sociological interpretation. Berkeley: University of California Press, 1984.

Sinani, E., Stafsudd, A., Thomsen, S., Edling, C. \& Randoy, T. 2008. 'Corporate governance in Scandinavia: Comparing networks and formal institutions', European Management Review, 5(1): 27-40.

Stearns, L. \& Mizruchi, M. 1986. 'Broken-tie reconstitution and the functions of interorganizational interlocks: A reexamination', Administrative Science Quarterly, 31: 522538.

Thompson, J. \& McEwen, W. 1959. 'Organizational goals and environment: Goal-setting as an interaction process', American Sociological Review, 23: 23-31.

Useem M. 1984. The inner circle: large corporations and the rise of business political activity in the US and UK. Oxford: Oxford University Press.

Wagner, A. 2001. 'The small world inside large metabolic networks', Proceedings of the Royal Society B: Biological Sciences, 268: 1803-1810.

Watts, D. 1999. Small worlds: the dynamics of networks between order and randomness. Princeton: Princeton University Press.

Watts, D. 2003. Six degrees The science of a connected age. Norton: WW Norton \& Company.

Watts, D. \& Strogatz, S. 1998. 'Collective dynamics of 'small-world' networks', Nature, 393: 440-442.

Zeitlin, M. 1974. 'Corporate ownership and control: The large corporation and the capitalist class', American Journal of Sociology 79:1073-1119. 